\title{
Eyelid Tightening and Improved Eyelid Aperture through Nonablative Fractional Resurfacing
}

\author{
Sean A. Sukal, MD, PhD, ${ }^{*}$ Anne M. Chapas, MD, ${ }^{* \dagger}$ Leonard J. Bernstein, MD, ${ }^{*}$ Elizabeth K. \\ Hale, MD, ${ }^{* \dagger}$ Karen H. Kim, MD, ${ }^{*}$ and Roy G. Geronemus, MD ${ }^{* \dagger}$
}

BACKGROUND AND OBJECTIVE The effects of fractional resurfacing on eyelid tightening and aperture
are unknown. Our purpose was to retrospectively examine the potential for eyelid tightening and eye-
aperture opening in patients treated with nonablative fractional resurfacing for facial photorejuvenation.

STUDY DESIGN/MATERIALS AND METHODS Fractional laser treatments using a 1,550-nm erbium-doped fiber laser system on the upper and lower eyelids were given at a pulse energy of 17 to $20 \mathrm{~mJ}$ at 125 micro-thermal zones (MTZ)/ $\mathrm{cm}^{2}$ to a final density of 500 to $750 \mathrm{MTZ} / \mathrm{cm}^{2}$. Each patient had 3 to 7 treatments. Standard pre- and post-treatment photographs were taken at each visit. Physicians who graded 31 preselected patient photographs using a 4-point scale evaluated eyelid tightening. Increase in eyelid aperture was also evaluated.

RESULTS All patients had some degree of eyelid tightening; $19 \%$ achieved $1 \%$ to $25 \%$ tightening, $26 \%$ achieved $25 \%$ to $50 \%, 26 \%$ achieved $50 \%$ to $75 \%$, and $29 \%$ achieved $75 \%$ to $100 \%$. Increase in eyelid aperture was seen in $55.9 \%$ of patients. Postoperative wounding, hypopigmentation, hyperpigmentation, persistent erythema, and scarring were not observed. All patients experienced mild or no edema for a few days after treatment.

CONCLUSION Fractional resurfacing tightens and increases eyelid aperture without wounding, downtime, or long-term complications.

Dr. Geronemus is a shareholder in Reliant Technologies.

$\mathrm{E}$ yelid laxity is often the cause of senile ectropion and entropion. It may also be associated with epiphora $^{1,2}$ and laxity of the medial and lateral canthal tendon. ${ }^{2,3}$ Lower eyelid laxity is a common problem in patients undergoing lower eyelid blepharoplasty. ${ }^{3}$ A variety of surgical techniques are available to tighten eyelids. ${ }^{4}$ Complications include overcorrection, undercorrection, suture abscess, exposed sutures, and suture breakage. ${ }^{4}$ A $20 \%$ reduction in blepharoplasty procedures from 2004 to 2005 suggests an increasing interest in nonsurgical options for eyelid rejuvenation. ${ }^{5}$ Nonsurgical options include laser resurfacing, ${ }^{6}$ chemical peels, ${ }^{7}$ and radiofrequency (RF) energy. ${ }^{5,8}$

Fractional photothermolysis (FP) has recently been introduced ${ }^{9}$ and reviewed in detail. ${ }^{10}$ The device is a 1,550-nm erbium-doped fiber laser system that produces arrays of micro-thermal zones (MTZs) of injury while sparing the surrounding tissue. These MTZs have 3-dimensional arrangements and are formed at specific depths in the skin. Although the entire epidermis is affected, only $20 \%$ of the epidermis (the MTZs) is treated in a single session. The stratum corneum is not damaged and acts as a natural bandage that protects the microscopic wounds as they heal within 24 hours. Unlike ablative and other nonablative laser devices, the FP device penetrates up to $1.4 \mathrm{~mm}$ into the skin. Erythema is mild, and downtime is minimal, permitting patients to apply cosmetics immediately after treatment. As in other laser modalities, multiple treatments are required for optimal results.

\footnotetext{
* Laser and Skin Surgery Center of New York, New York, New York; ${ }^{\dagger}$ Department of Dermatology, New York University Medical Center, New York, New York
} 
FP treatment leads to collagen remodeling and new collagen formation after the incipient inflammatory cascade. Short-term adverse effects of full face treatment have been described. ${ }^{11}$ These most commonly included transient post-treatment erythema, facial edema, dry skin, flaking, a few superficial scratches, pruritus, and bronzing. The use of forced cold air during treatment has been shown to reduce discomfort. ${ }^{12}$ The technique has been used to treat scars,${ }^{13-15}$ poikiloderma of Civatte, ${ }^{16}$ pigmentation, ${ }^{17,18}$ poor skin texture, ${ }^{18}$ melasma,,${ }^{19,20}$ and facial aging. ${ }^{21}$

Our purpose was to retrospectively examine the potential for eyelid tightening and eye-aperture opening in patients undergoing fractional resurfacing for facial photorejuvenation.

\section{Methods}

The records of 31 patients with a mean age \pm standard deviation of $55.3 \pm 11.3$ and primarily Fitzpatrick skin types I and II (one Asian patient was skin type IV) were evaluated. Patients with reproducible photography adequate for comparative purposes were included in this study. The Fraxel 750 SR laser (Reliant Technologies Inc., Mountain View, CA), a 1,550-nm erbium-doped fiber laser system, was used to treat the upper and lower eyelids at a pulse energy of 17 to $20 \mathrm{~mJ}$ at 125 microthermal zones (MTZs) $/ \mathrm{cm}^{2}$ to a final density of 500 to $750 \mathrm{MTZ} / \mathrm{cm}^{2}$ using the $15-\mathrm{mm}$ treatment tip. Each patient had 3 to 7 treatments, 2 to 3 passes per area, after application of topical anesthesia. Eye shields were not used during treatments. Our technique for upper eyelid treatment was to retract the eyelid skin over the orbital rim while the patient maintained closed eyes. Treatment sessions were 3 to 4 weeks apart. Treatment time for the eyelids was just seconds. Standard pre- and post-treatment photographs were taken at each treatment session. Posttreatment photographs were taken 3 to 4 weeks after the last treatment in all cases. Three physicians assessed eyelid tightening from photographs of 31 patients using a 4 -point evaluation scale $(1=1-25 \%$,
$2=26-50 \%, 3=51-75 \%$, and 4=76-100\%. Eyelid apertures were judged as larger or not changed. If eyelid aperture appeared to decrease (as when the patient blinked), the result was recorded as "not changed." Only patients with multiple evaluable photographs were selected for the study. Hooding of the upper eyelids was included as a feature for tightening and was not evaluated separately.

To ascertain the source of eyelid tightening after fractional resurfacing, measurements of all our standard photographs were made. A horizontal line connecting the medial and lateral canthi of each eye was used as a standard for the purposes of comparison of pre- and post-treatment photographs. From this line, a perpendicular vertical line through the pupil to the supraorbital fold was constructed and measured. A similar measurement was made to the upper margin of the brow. Percentage change in the position of the supraorbital fold and brow was calculated for each eye.

\section{Results}

Grades of the 3 evaluating physicians were analyzed using Kruskal-Wallis analysis of variance (ANOVA), the non-parametric equivalent to 1-way betweensubject ANOVA. The median grades of the 3 physicians for all patients did not differ significantly $(p=.22)$ from one another, indicating unbiased grading among the physicians.

All patients achieved a degree of eyelid tightening; $28 \%$ achieved $1 \%$ to $25 \%$ improvement, $26.9 \%$ achieved $25 \%$ to $50 \%, 25.8 \%$ achieved $50 \%$ to $75 \%$, and $19.4 \%$ achieved $75 \%$ to $100 \%$ (Figure 1 ). Increase in eyelid aperture was seen in $55.9 \%$ of patients (mean of 21/31, 15/31, 16/31). Scarring, hypopigmentation, hyperpigmentation, persistent erythema, and postoperative wounding were not observed.

Measurements of standardized photographs showed that the percentage of eyelids demonstrating a lift in 

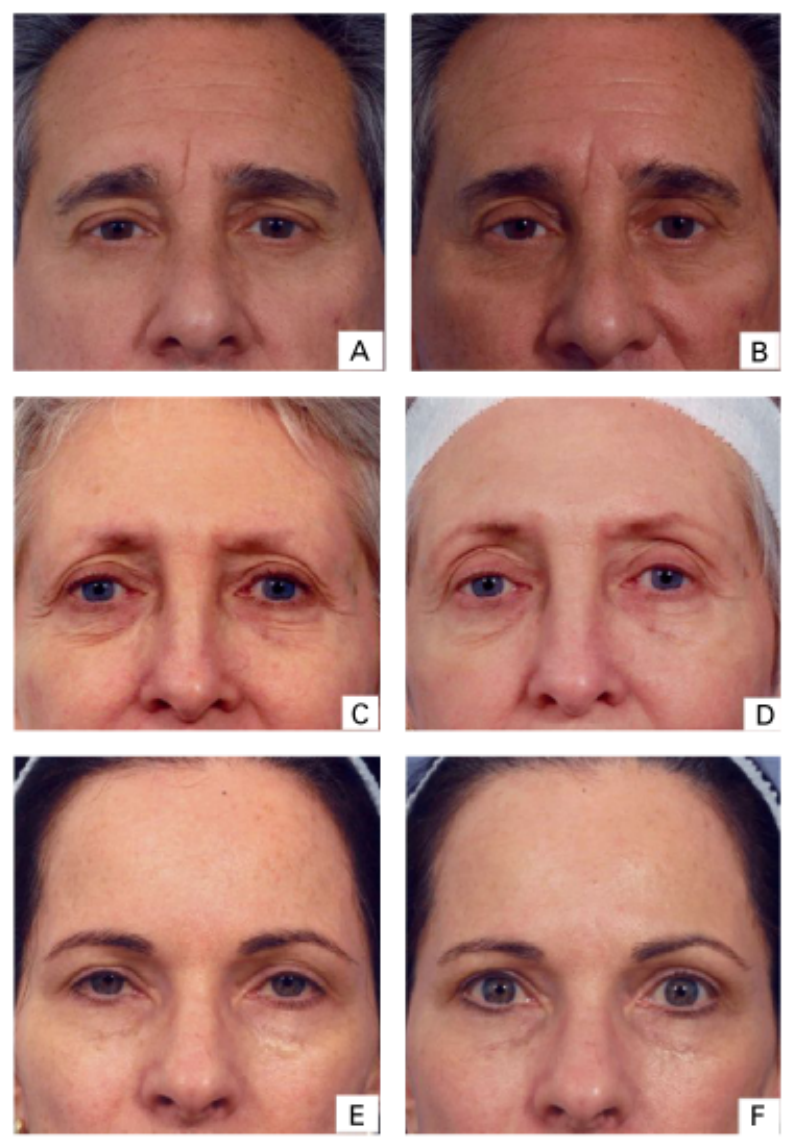

Figure 1. Baseline ( $A, C$, and $E$ ) and follow-up (B, D and $F$ ) photos 1 month after third fractional photothermolysis treatments of upper and lower eyelids from the lid margin to the orbital rims at a pulse energy of 17 to $20 \mathrm{~mJ}$ at $125 \mathrm{MTZ} / \mathrm{cm}^{2}$ to a final density of 500 to $750 \mathrm{MTZ} / \mathrm{cm}^{2}$.

the brow position was $26 \%$, compared with $44 \%$ showing lifting of the supraorbital fold.

\section{Discussion}

This retrospective study suggests that the eyelids of most patients treated using fractional resurfacing can be tightened at least $25 \%$ and that the eyelid aperture can be increased in more than half of patients without wounding or downtime.

It is likely that the improvement in eyelid aperture and eyelid tightening resulted from treatment of the eyelids themselves, concomitant treatment of the forehead and upper cheeks that may improve aperture and lid laxity by creating a brow lifting effect or lower-cheek tightening, or a combination of these factors. Because all patients had full face treatments, we sought to establish the source of the clinically observed effect. This was done by quantitating improvement in brow position and supraorbital fold position to see whether changes in these could account for what was clinically observed. The data clearly demonstrate that far more improvement arose from actual lid tightening that resulted in changes in the supraorbital fold position, whereas only a small contribution to eyelid tightening came from changes in brow position achieved through forehead lifting. Future work will establish whether solitary treatment of the eyelid with exclusion of the forehead would achieve similar results.

Protective eye shields were not used in the treatments included in this study because none of the treatments were performed directly overlying the globes. Upper lid treatments are done by retracting the upper lid over the orbital rim. Our practice is to limit our treatment areas to the part of the eyelid that can be retracted over the orbital rim; the treatment tip is never placed below the orbital rim directly over the orbit. In addition, treatment settings for eyelids are typically lower than those for non-eyelid skin because of the thinness of eyelid skin. Should treatment of the entire lid, including the lid margin, be attempted, it would be advisable to use eye shields to ensure safety of the globe.

The use of lasers in the treatment of eyelids is not new but is often limited by prolonged postoperative wounding, persistent erythema, and the potential for hypopigmentation and ectropion. The carbon dioxide laser, for example, has been evaluated for eyelid resurfacing, including wrinkle reduction. ${ }^{6}$ Wrinkles were reduced at least $70 \% 3$ to 6 months after treatment in $65 \%$ of cases, and improvement continued for up to 6 months. Adverse effects included erythema that resolved in 4 weeks in $80 \%$ of patients and edema that resolved after 4 to 6 weeks. The authors also reported a small degree of tissue contraction. 
Lower eyelid laxity has also been corrected by nonablatively treating the periorbital area with RF energy. ${ }^{8}$ In a 9-patient study, Ruiz-Esparza attributed cosmetic improvement of the eyelids to skin contraction. Improvement occurred gradually, patient satisfaction was high, and complications were not observed. This procedure did not correct fat herniation and muscle atrophy in the lower eyelid. Efficacy was assessed by evaluating photographs taken at various times after the single

treatment.

A recent 72-patient study ${ }^{5}$ of the use of RF energy (Thermage, Inc., Hayward, CA) delivered through a $0.25-\mathrm{cm}^{2}$ tip for the treatment of eyelids showed that upper eyelid tightening was achieved in $88 \%$ of subjects and lower eyelid tightening was achieved in $71 \%$ to $74 \%$ of patients. Most patients obtained at least $25 \%$ improvement, which is comparable with the results of the present study. However, the RF technique is slow and laborious, and a single treatment session requires up to 1 hour for the eyelids, whereas the nonablative fractional resurfacing technique requires only seconds. In addition, the nonablative fractional resurfacing technique requires no special preparation or attachments other than what is required to treat the remainder of the face.

Studies on increasing the eyelid aperture are few. The integrity of the eyelids and the surrounding orbital structures affect the palpebral aperture. ${ }^{22}$ Abnormalities have been corrected surgically, ${ }^{23}$ and increases have been achieved by injecting botulinum-A toxin. ${ }^{24}$ Fractional resurfacing appears to be a new treatment option for widening this opening, with no postoperative morbidity, appreciable discomfort, scarring, persistent redness, or permanent pigmentary alteration.

The effects on eyelids described in this study were unanticipated and were not intended at the time of treatment. Indeed, one weakness of this study is its retrospective nature. The treatments were originally intended to improve texture through photorejuve- nation of the entire face. No attempts were made a priori to standardize treatments with respect to number of treatments and number of passes, because we typically tailor our therapy to each patient's individual needs and tolerability. Future prospective work may lead to improved methods of achieving equivalent or better results than those presented here. This rapid method of treating eyelids may also be further improved using modifications or refinements of the technique and as fractional technology advances.

\section{Conclusion}

Fractional resurfacing effectively tightens and increases the aperture of eyelids, giving a more youthful appearance to the aging face without wounding, downtime, or long-term complications.

\section{References}

1. Hurwitz JJ, Mishkin SK, Rodgers KJ. Modification of Bick's procedure for treatment of eyelid laxity. Can J Ophthalmol 1987;22:262-5.

2. Fante RG, Elner VM. Transcaruncular approach to medial canthal tendon plication for lower eyelid laxity. Ophthalmol Plast Reconstr Surg 2001;17:16-27.

3. Patipa M. Lateral canthal tendon resection with conjunctiva preservation for the treatment of lower eyelid laxity during lower eyelid blepharoplasty. Plast Reconstr Surg 1993;91:456-62.

4. Liu D. Lower eyelid tightening: a comparative study. Ophthalmol Plast Reconstr Surg 1997;13:199-203.

5. Biesman BS, Baker SS, Carruthers J, et al. Monopolar radiofrequency treatment of human eyelids: a prospective, multicenter, efficacy trial. Lasers Surg Med 2006;38:890-8.

6. Harris DM, Fried D, Reinisch L, et al. Eyelid resurfacing. Lasers Surg Med 1999;25:107-22.

7. Dailey RA, Gray JF, Rubin MG, et al. Histopathologic changes of the eyelid skin following trichloroacetic acid chemical peel. Ophthalmol Plast Reconstr Surg 1998;14:9-12.

8. Ruiz-Esparza J. Noninvasive lower eyelid blepharoplasty: a new technique using nonablative radiofrequency on periorbital skin. Dermatol Surg 2004;30(2 Pt 1):125-9.

9. Manstein D, Herron GS, Sink RK, et al. Fractional photothermolysis: a new concept for cutaneous remodeling using microscopic patterns of thermal injury. Lasers Surg Med 2004;34:426-38.

10. Geronemus RG. Fractional photothermolysis: current and future applications. Lasers Surg Med 2006;38:169-76. 
11. Fisher GH, Geronemus RG. Short-term side effects of fractional photothermolysis. Dermatol Surg 2005;31(Pt 2):1245-9.

12. Fisher GH, Kim KH, Bernstein LJ, Geronemus RG. Concurrent use of a handheld forced cold air device minimizes patient discomfort during fractional photothermolysis. Dermatol Surg 2005;31(Pt 2):1242-4.

13. Behroozan D, Gliach AS, Goldberg L, et al. Fractional photothermolysis for treatment of surgical scars: a case report. J Cosmet Laser Ther 2006;8:35-8.

14. Hasegawa T, Matsukura T, Mizuno Y, et al. Clinical trial of a laser device called fractional photothermolysis system for acne scars. J Dermatol 2006;33:623-7.

15. Rokhsar CK. Nonablative fractional laser resurfacing for atrophic an acne scarring. J Cosmet Dermatol 2006;19:742-4.

16. Behroozan D, Goldberg L, Dai T, Friedman P. Fractional photothermolysis for treatment of poikiloderma of civatte. Dermatol Surg 2006;32:298-301.

17. Lask GP. Managing superficial pigmentary alterations with the Fraxel laser. Pract Dermatol 2006.

18. Rahman Z, Alan M, Dover JS. Fractional laser treatment for pigmentation and texture improvement. Skin Therapy Lett 2006;11:1-6.
19. Rokhsar CK, Fitzpatrick R. The treatment of melasma with fractional photothermyolysis: a pilot study. Dermatol Surg 2005;31:1645-50.

20. Tannous ZS, Astner S. Utilizing fractional resurfacing in the treatment of therapy-resistant melasma. J Cosmet Laser Ther 2005;7:39-43.

21. Bass LS. Rejuvenation of the aging face using Fraxel laser treat ment. Aesthetic Plast Surg 2005;25:307-9.

22. Jelks GW, Jelks EB. The influence of orbital and eyelid anatomy on the palpebral aperture. Clin Plast Surg 1991;18:183-95.

23. Yaremchuk MJ. Restoring palpebral fissure shape after previous lower blepharoplasty. Plast Reconstr Surg 2003;111:441-50.

24. Flynn TC, Carruthers JA, Carruthers JA. Botulinum-A toxin treatment of the lower eyelid improves infraorbital rhytides and widens the eye. Dermatol Surg 2001;27:703-8.

Address correspondence and reprint requests to: Roy G. Geronemus, MD, Laser \& Skin Surgery Center of New York, 317 East 34th Street, New York, NY 10016, or e-mail: rgeronemus@laserskinsurgery.com 